\title{
Economics and ethics in health care
}

Anthony J Culyer University of York,

\begin{abstract}
This editorial provides a review of the current ways in which health economics is impacting on policy and reviews some of the key ethical and value-judgmental issues that commonly arise in and as a result of the work of economists. It also briefly highlights the contributions of the authors of this special issue of the journal, all of which illustrate how economists have approached ethical issues in health service policy (both in its financing and its delivery), and some of which explore the major methodological matters that arise and go on to discuss their potential as sources of conflict or harmony with other approaches to the same questions.

(Fournal of Medical Ethics 2001;27:217-222)
\end{abstract}

Keywords: Health economics; value judgments; resource allocation; ethics; QALYs

\section{Introduction}

The main idea behind this special issue of the journal was to provide a "snapshot" picture of what economists have (and have had) to say about some of the key ethical and value-judgmental issues that arise in financing and providing health care subject to resource constraints, which is, of course, the universal situation though the constraints in some countries bite harder than others. The picture was also intended to convey what economists are thinking about their approaches to these questions as well as the substantive things they have to say about them.

While the questions are universal and timeless, there are several reasons why it is particularly timely to consider the way in which health economics and ethics interact and how economists have approached the many value-judgmental issues that arise in their research and policy advice. One is that economics has now come of age as one of the key disciplines that underpin a good deal of policy-at least in the UK. The recent white paper, The NHS Plan: a Plan for Investment, a Plan for Reform, devoted an entire chapter (chapter 3) to a discussion of the pros and cons of alternative means of funding health care in the UK in which the ethics of both efficiency and equity were reviewed for the first time in such a document. Moreover, the National Institute for Clinical Excellence (NICE) is a key element in the UK government's reforms of the National Health Service (NHS) in England and
Wales and it uses economics explicitly in its appraisal of technologies for possible use in the NHS and as a part of its clinical guideline development programme. For this reason alone, it seems appropriate to review how it is that economists set about the ethical issues that arise, partly to encourage wider professional participation and partly to support the increasing lay participation in health care decision making at all levels in the UK by making explicit and accessible what may otherwise be hidden within arcane processes and too technical to enable wider dialogue. Another reason is that economists (or, come to that, other professional groups) are not qualified to make the value judgments that are embodied in decisions. They are rather good at identifying the necessity for making value judgments and at spelling out the nature of the value judgments that are needed. They are often forced to make value judgments in the absence of any other more appropriate mechanism for making them but value judgments made in this way must be seen as provisional, or as cockshies to focus the attention of better qualified others to engage with the issues. Such value judgments cannot be regarded as authoritative or as having been arrived at through an authoritative process. Indeed, some economists have devoted a good deal of energy to devising experimental procedures for yielding value judgments, for example by asking lay people in systematic ways to reveal them. A third reason is that economists, along with many others, have recently devoted much thought to the question of equity, both in general theorising about it and in the context of national and international programmes which have increasingly come to be seen as needing to address issues of equity through explicit analysis rather than merely by largely empty posturing and sloganising.

The kind of value judgment that economists have mostly been concerned with relates to the objectives of health care systems, to distributive justice, and to ways of resolving clashes between efficiency (maximising something subject to resource constraints) and equity (distributive fairness). A good example of the first of these is the question of what health services are for. The usual approach adopted by economists is to assume that the objective is a weak form of utilitarianism, so that the test of an improvement in social welfare becomes the Paretian one of whether any change can be made that 
(after compensation via market and other transactions) increases any individual's welfare without reducing anyone else's. If so, the change ought to be made (it would increase efficiency); if not, the change ought or ought not to be made-the test cannot tell since it does not allow interpersona welfare comparisons. It is silent (hence the "weakness" of this brand of utilitarianism). Many health economists, however, adopt a different approach to the social maximand. Instead of postulating a Paretian-style utilitarian objective, they are more empirical, drawing on evidence about what it seems that those with "legitimate" authority (such as government ministers?) seem to think the objective ought to be and being much less squeamish about making interpersonal comparisons. Using this approach, health economists have tended to take, as an approximation to the objective, the maximisation of "health" or "health gain", which are oft-stated ministerial objectives. But there are two ethical issues that immediately arise (and which most health economists have been very explicit about): one is indeed the question of what the objective ought to be (and the related question of what or who is to be regarded as an "authoritative" source) but the other is the question of what "health" or "health gain" is to be taken as meaning. In the case of the latter question, the typical approach is reductionist and the following "ought" questions arise (I make no claims to exhaustiveness here). Which aspects of human functioning ought to be taken into account? How ought they to be scaled in terms of "better" or "worse"? How "strong" ought the scaling measurement to be (ordinal or cardinal)? How ought different ratings of different aspects be combined or traded off? What "utility" score ought to be attached to combinations of ratings? Ought the resultant "utilities" to be discounted when they relate to future health states and, if so, at what discount rate? Should they be further discounted for uncertainty and, if so, how? What weight should be attached to rated health states accruing to different people (the relatively healthy compared to the relatively sick, young relative to old, rich relative to poor, chronic sufferers compared to acute, and so on)? As the list makes clear, questions of distributive fairness lurk even within a question that began as one of efficiency.

\section{Long history}

The ethical questions of how best to finance health care and regulate its production and distribution have a long history in health economics and, indeed, may be said to have been the questions that set the subject off. ${ }^{2}$ Economists have been divided on the "right" answers to these questions, broadly falling into "libertarian" and "collectivist" camps (these are very loose terms)-that is, when they go beyond mere economics and engage in advocacy (see Towse $^{3}$ for an example of such a division, $\mathrm{Cu}$ lyer, Maynard and Williams ${ }^{4}$ for relative objectivity and Culyer and Evans ${ }^{5}$ for a scolding).
In contrast to this "high level" sort of ethical debate, it is easy to see that the increasing explicitness of health care decision making (albeit still at quite a high level, organisationally speaking) will inevitably focus attention on difficult ethical posers that were previously fudged. Explicitness is largely taken for granted by economists as a desideratum. Some of these issues can be well illustrated by using a UK example-the recent creation of the National Institute for Clinical Excellence referred to earlier. The National Institute for Clinical Excellence is required to make recommendations to the NHS as to the medical technologies that ought to be used to maximise health gain and to develop authoritative clinical guidelines for medical and other practitioners. Cost-effectiveness is a major consideration and health gain is taken as a major maximand. The most widely used measure of health gain is the Quality Adjusted LifeYear (QALY) which has the advantage that it enables inter-technology comparisons to be made. As a first approximation, maximising health gain entails setting the cost per QALY as near as possible to equality across all technologies. Thus, technologies with a "low" cost per QALY (at a relevant margin) are to be preferred to those with a "high" cost per QALY (again at the margin). The logic is straightforward: if resources were to be transferred from a high to a low cost per QALY technology, keeping the effective budget for the NHS constant, overall health gain would rise and would continue to rise until (at the margin) the cost per QALY for each conceivable technology was brought into equality. If health maximisation is an ethical objective, then the use of such a method is also ethical (provided, of course, it is done in a way that does not violate other ethical desiderata). Over time (and it may be only a very short time), it is apparent that there will emerge a marginal cost per QALY that becomes a kind of threshold-a technology lying above it (at the margin) will not be recommended. Such a threshold has never been made public or subject to public discussion (at least in the UK). Yet it appears inevitable that it will emerge (or be deduced by keen-eyed observers). Its emergence (or deduction) will play a critical role in debates about the appropriate size of health care expenditure, because those denied benefit (whether manufacturers or patients) will see that the argument has to shift from one about shares of spending to the overall level of spending. Expectations about what can be expected from increased spending will become much more focused and policy too will become much more focused. Indeed, it is possible to see the UK experiment with clinical governance as essentially being about just such a focus: a means of assuring central budget-holders that additional expenditures will generate real improvements in health rather than simply creating rents for those who provide care and perpetuating inefficient resource allocations.

\section{Citizens Council}

The National Institute for Clinical Excellence will also confront explicitly the question of which values 
are to be adopted in QALY (or any other) outcome measures. In the UK, the setting up of a Citizens Council was motivated by just such a consideration. The government's idea here is that important matters of ethical judgment (of which the ethics embodied in QALYs must surely count as amongst the most important) ought to be tackled by a representative sample of the general population. This form of "citizens' jury" is thus seen as one answer to the question of the "authoritative" source of value judgments.

\section{Dearth of evidence}

The National Institute for Clinical Excellence's decision making will also inevitably cause it to confront possible clashes between efficiency and distributive fairness. Whereas ethicists, like economists, are likely to have considered such conflicts mainly in the abstract (or at least in imaginary circumstances), NICE decision makers will have to consider them in concrete circumstances. The National Institute for Clinical Excellence's inheritance included a dearth of evidence on costeffectiveness and some patchy evidence of inequity (one type of which is often described as "post code prescribing", according to which what you get depends on where you live). Now consider a scenario in which a particular treatment for a chronic condition had an unknown costeffectiveness and, as a consequence, was available in some localities but not in others because different local decision makers reached their own conclusions as to whether to fund it. Suppose NICE determines that the cost-effectiveness of the treatment lies well above any threshold cost per QALY. The recommendation on efficiency grounds is clear: do not use. Let us take a prime principle of distributive fairness to be a form of horizontal equity: persons in like need ought to be treated in the same way. Three possibilities now suggest themselves: (1) withdraw the treatment from those already receiving it, (2) retain the treatment for those receiving it but do not prescribe it for new patients, (3) allow all to receive it for whom it is judged appropriate by their doctors, even though it is inefficient. Which option should be chosen? Economics cannot provide the answer (though it may provide some relevant information to aid those who have to answer the question), neither can medicine or epidemiology, since no practitioner of these sciences is especially qualified to make value judgments on behalf of the rest of us.

There are a great many attractions to settling ethical matters such as these by reference to an "authoritative" source of value. One is that it opens an ethical debate about what kind of "authority" ought to exist to guide those empowered to make practical decisions about procedures. Another is that it defines roles: the professions involved in making the scientific judgments can provide the essential contextual information to inform those authorised to make, or advise on, the value judgments. Another is that it stops scientists from injecting (imposing?) their own value judgments, using their scientific expertise to lend a spurious authority to their values and preferences. But the principal advantage is that such procedures are open (and hence challengeable both as regards procedure and as regards the outcome of the procedure) and also have a degree of "authority" that would otherwise be lacking.

Evidence-based policy and evidence-based medical practice need, most economists would agree, an evidential base for their value-judgmental content. The ballot box serves only for the broadest of values. At more specific levels, the interaction between those whom it is decided ought to determine the values required for a particular purpose and those with technical knowledge, understanding and the ability to specify (at least some of) the key value judgmental issues, seems to beckon in a new era of what might be termed "empirical ethics". This is not "applied ethics" in its usual sense but the study of the quantification of particular kinds of ethical value. Economists have played a major role in ushering in this new era-and in defining the issues that empirical ethics might usefully address.

\section{The articles in this issue}

Alan Maynard's article is a thought-provoking attack on the implicitness of so much ethics in health care and the arbitrary outcomes that arise in the absence of systematic facing-up to, and obfuscation of, the central issues involved in allocating health care resources: being clear about objectives and analytical about the means of achieving them. He argues pugnaciously for explicitness on the grounds that it is a protection against self-seeking behaviours and is more likely to deliver the objectives sought, and that without it policy makers and practitioners cannot be held to account (apparently even in the next world, though that begs a question about the information base available there for such ultimate judgments!). He does not specify the sorts of means he judges to be appropriate instruments for his idealised health care system based on science and rationality but it would certainly be possible to see a good deal of the UK Labour government's programme for the NHS as offering a comprehensive attempt to achieve just what he is advocating.

Bosanquet takes economists to task for not adopting the research agenda he prefers. $\mathrm{He}$ is almost certainly wrong, however, in saying that economists have become too concerned with equity questions-had they achieved more in this regard, the NICE guidance on how to conduct technology appraisals would not have been the weak affair that it is in respect of guidance on how to handle equity matters. He is surely right, however, in observing that our understanding of behaviour-governing and regulatory frameworks to promote evidence-based, cost-effective and, come to that, equitable practice is very poor. A characteristic of nearly all the literature of health economics since its inception ${ }^{2}$ is its focus on the demand side. Nearly all the theory used to underpin arguments for public health 
insurance and heavily publicly subsidised services are arguments from the demand side. None of these arguments has any bearing on the relative problems and costs of public provision versus public contracting with private providers which the uncontrolled experiment with public agencies "contracting" with providers in (and later increasing outside) the NHS in the UK actually shed little light upon (but see Chalkley and Malcomson ${ }^{6}$ for a survey). So there remains a big question on the efficiency agenda: what ought the balance between private and public provision within a public (but not necessarily publicly owned) service to be, and through what instruments might an efficient balance be attained? Viewed in terms of outcomes, the ethics in this question are primarily to do with the ethics of efficiency itself: the efficient balance (that is, the balance that maximises the value of outcomes for given resources) and the equitable balance (that is, the balance that delivers equity objectives) will be ethical balances by virtue of their delivering efficiency in both and in the trade-off between them when there is conflict. But there may also be processes as well as outcomes whose equity requires evaluation. This is an interesting and important agenda.

\section{Market failures}

The demand-side nature of the economics of public finance for health care is well illustrated by Hurley's article. He explores three approaches to the welfare economics of health care: classical utilitarianism, extra-welfarism and Rawlsian contractarianism. He advocates an instrumentalist approach to the meaning of the "need" for health care-the entity asserted to be needed must be needed for an ethical end (such as human flourishing) and the entity must be effective (possibly cost-effective) in serving that ethical end. He identifies the market failures that can prevent the attainment of an efficient allocation of resources for meeting needs as well as the equity desiderata that are hard for market methods to deliver, most of which stem from the universal truth that wealth and health are positively correlated in societies, which means that provision has to be directed at need rather than demand and that health insurance has to find a way of reversing the natural state in which those least able to pay for it are most in need of it. Like other authors in this issue, he makes a strong claim on behalf of economics as a taxonomising device: clarifying concepts in relevant ways, breaking them up into specific manageable issues in the classic reductionist fashion, quantifying them where possible, and offering them up as topics for multidisciplinary inquiry.

Rice considers the standard utility-maximising approach of welfare economics as applied to health care as supplemented by liberal and libertarian arguments for distributive fairness in the context of the rights of individuals to autonomy in choice. This is contrasted with views that give health care (or, perhaps, health) the special status of a primary good and emphasise greater equality at the price of a sacrifice of individual autonomy. Efficiency arguments, let alone equity ones, for market-based freedom of choice fail on grounds of externality-which goes to show that even economic reductionists can provide examples of the whole being greater (or smaller) than the sum of the parts! There is a strong case to be made on both sides but he concludes that one primary good (health) trumps another (freedom from interference) on the ground that endowed allocations of health are inherently arbitrary, as are efforts to separate ill health into that which is self-induced (unworthy of public support) and that which is random (worthy of public support). Not explicitly stated, though it seems implicit, is another ground: that health trumps freedom because it is usually a necessary condition to have the one in order to be able to enjoy the other.

Dowie uses the ideas of cost-effectiveness and QALYs to open up some ethical issues in both the way health economists do their work and communications across disciplines. The ground is cleared by an uncompromising classification of health economists as "analytical consequentialists" (being neither intuitionists nor absolutists) and by making clear that the oft-misunderstood concept of opportunity cost means health gain deliberately forgone as an act of choice. With this uncompromising opening, he then dissects the objections that have been made to the economic approach in the contexts of both efficiency and equity and concludes that much of the opposition has actually taken the form of a search to achieve a particular form of ascendancy through the application of double standards. Thus, those adopting intuitive approaches to questions of ethics in health care have required those taking an analytical approach (ie economists) to convey the analytical case in intuitive terms (or else they judge it to have failed). Those approaching ethical questions in health with an analytical approach are usually adept at identifying analytical and empirical weaknesses (that is, after all, why they are analysts and they are usually much better at it than the intuitionist opposition). These are then held up as "weaknesses" by the intuitionists, even though their own method masks any specific "weaknesses". Moreover, not being analytical, intuitionists are not usually very good at tackling weaknesses (for example, by turning them into strengths) or identifying the circumstances under which the weaknesses are likely to mislead (or even cripple) and are hence not to be used.

\section{Empirical approach}

Williams argues for an empirical approach to answering the key ethical questions that arise in fairly high level decision making contexts, where ethical impasses are often reached, such as how efficiency and equity ought to be traded-off when they conflict, or which ethical basis for assessing equity ought to be adopted. He observes that views about ethical issues are rarely simply binary (for example, "important", "not important") but reflect 
strengths of view which vary according to "how much" of an inefficiency or inequity may exist, and its character, and which also vary across individuals and for each individual over time. The issues then become those of identifying those who are to be the appropriate "authorities" (or who may have the "authority" to make recommendations to a higher "authority") and of devising experimental methods to reveal the trade-offs that the selected subjects actually make when confronted with actual choices. $\mathrm{He}$ reviews and rejects a number of objections to "quantification" (for example that it lacks sensitivity to the "infinite variety of human experience", and that it is "mechanistic") which hark back to Dowie's discussion of intuitionist objections to the analytical approach.

\section{Territorial equity}

Rice and Smith examine territorial equity, such as the ethical issues arising in the allocation of budgets to health care commissioners (health authorities and primary care trusts in the UK) or regions in other countries such as New Zealand. They refer to the extensive evidence on variations between areas in terms of health and intervention rates that seem to be explained only by region of residence or treatment and have little relation to any underlying epidemiology, morbidity or clinical need. The issues that arise are problems in both vertical and horizontal equity. They argue for capitation-based systems that distinguish between "legitimate" determinants and "illegitimate" determinants of what expenditure ought to be. Historical utilisation is criticised as a determinant because it fails to take account of need, much of which may have been unmet (to use historical utilisation would imply that inherited unmet needs are unimportant). They conclude that policies to reduce arbitrary geographical inequalities can best be couched in terms of those which tackle variations in the quality of care, variations in the accessibility of care and factors outside the control of health care agencies Clinical governance or other forms of performance management may be the primary method for dealing with quality variations; supplementary resource allocations may be the most effective way of tackling variations in accessibility. Tackling the third source of variation may require explicit preferential access (and resourcing) and the abandonment of clinical need as an indicator of regional differences in need, together with a more joined-up approach that addresses a wider set of policies directed at health rather than just the health care services themselves.

Wagstaff addresses an even higher level equity problem: that facing the World Bank in helping countries to improve the health of the poor and reduce the impoverishing effects of illness. The character of the issues is not, however, so very different from those discussed by other authors: the question of trade-off (here, for example, between overall increases in health and reductions in the health differences between the health of the rich and poor) and the use of analysis (here, for example, the properties of different weighting schemes and the degree to which they meet ethical distributional criteria). A matter that is also touched on by Rice and Smith in this issue of the journal relates to the question of whether all inequalities are equally bad, to which one answer appears to be that those that matter are those that arise from differences in the constraining (full) prices people confront rather than the choices they make when they have the same opportunities. These "prices" are not just a question of money but also relate to time costs, distances from health care facilities and a host of other factors that make the effective price higher than the money price and that cause substantial differences in the opportunities confronting different people in the same country. Such considerations also raise the issue of whether policies directed at health improvements and reductions in health inequity might be better implemented through poverty reduction programmes and other non-health care means rather than through health care. Then there are (even higher) levels of equity to be addressed-for example, inter-country allocation-and the extent to which it is proper to take account of the integrity of local governance structures and practices, the degree of local "ownership" and control that is both fair and effective (and the associated trade-offs that may be inherent here). The issue of public versus private provision in the context of a publicly financed health care system is also raised, as is the Rawlsian issue of whether international agency support that improves the lot of the well-off as a means of improving that of the poorly-off is ethically justifiable (supposing, of course, that there was a firm evidence base for believing that it actually works in practice).

\section{Cost-effectiveness principles}

Weinstein tackles the trade-off issue at a lower level-that of the physician as gate-keeper. At a sufficiently high level, the decisions are not about identified individuals whose personal circumstances are known (perhaps intimately) to the decision maker but about classes of persons such as people in a particular social class, or income category, or those having particular family responsibilities, or having a particular disease. At this level, questions are about the terms on which services are to be made available and to whom. The benefits to one group are compared (at the margin) with those to another (again at the margin) in order to maximise something (such as health) and to secure an equitable distribution of something (such as access or equity). Even if all these issues have been settled in some way deemed to be satisfactory, there remains the issue of how similar types of resourceconstrained decision are to be made at the level of the individual-for example, comparing the likely benefit to the patient in front of the doctor with the potential benefit to one who has yet to appear. Weinstein contrasts the agency role of a physician seeking the best for her own patients with the physician in a different agency role: seeking the best for 
society as a whole. His analysis suggests that cost-effectiveness principles, consistently applied, can generate guidelines for decisions that do not involve the doctor in invidious breach of the trusting relationship with patients. He suggests that this is made much more effective if doctors' choices are governed by well-designed incentives (for example, capitation payment may be preferable to fee-forservice), suitably designed budgets (in order to reduce the prevalence of sub-optimising), welldesigned clinical guidelines (coupled with a degree of permitted flexibility in their use) and a major attempt at public education and public enlistment in the business of what in the UK would be called clinical governance. It is likely that the kind of "buy-in" he seeks is more easily obtained in the UK and other countries with a tradition of more-or-less open acknowledgment of resource limitations in health care than in the USA.

Finally my own paper discusses conflicts between concepts of equity. A common focus of economists has been on the potential conflict between equity and efficiency. There are, however, important conflicts between equity concepts which even a pluralist approach cannot accommodate. Within one approach to equity (meeting needs equitably) the ambiguities of the term "need" are explored and a resolution suggested. Some of the other key issues needing to be resolved are identified, their significance explained, and their consequences for policy outlined.

There are, of course, many aspects of medical ethics that economists have not actively considered and, of those they have, the ones discussed in this issue of the journal is but a subset. I hope none the less that the range is sufficiently broad to engage the interest of non-economist readers and to enable and encourage them to enter into more effective dialogues with economists. One reassuring thing ought to be clear: health economists have a good track record of collaboration with the practitioners of other disciplines and recognise the need for such collaboration if the research programmes they aspire to are to be developed as well as they ought to be. Moreover, there are now policy customers "out there" for the sort of work to be done, so the environment could scarcely be more conducive to such work than it currently is.

Anthony $\mathcal{7}$ Culyer is Professor of Economics, Department of Economics \& Related Subjects, University of York, Heslington, York.

\section{References}

1 Department of Health. The NHS plan: a plan for investment, a plan for reform. London: HMSO, Cm 4818-I, 2000.

2 Arrow K. The welfare economics of medical care. American Economic Review 1963;53:941-73.

3 Towse A, ed. Financing health care in the UK: a discussion of NERA's prototype model to replace the NHS. London: Office of Health Economics, 1995.

4 Culyer AJ, Maynard AK, Williams A. Alternative systems of health care provision: an essay on motes and beams. In: Olson health care provision: an essay on motes and beams. In: Olson M, ed. A new approach to the economics of health care. Washington and London. American Enterprise Institute, 1982: 131-50. 5 Culyer AJ, Evans RG. Mark Pauly on welfare economics: normative rabbits from positive hats. Fournal of Health Economics 1996;15:243-5

6 Chalkley M, Malcomson JM. Government purchasing of health services. In: Culyer AJ, Newhouse JP, eds. Handbook of health economics [vol 1A]. Amsterdam: Elsevier, 2000: 847-90.

\section{News and notes \\ International Symposium: The State of ART Regulation- International Perspectives}

A one-day international symposium, The State of ART Regulation-International Perspectives, will be held in Melbourne, Victoria, Australia on Friday November 232001.

Participants at the symposium will hear from expert speakers about the status of regulation of assisted reproductive technology in different countries around the world and discuss the challenges faced by those regulating and accrediting infertility services. The symposium will be held prior to the 17 th world Congress on Fertility and Sterility, which is scheduled for November 242001 to December 1 2001.

Presentations providing an overview of Europe, New Zealand, the USA and Australia are now confirmed, and other presentations are being finalised. The afternoon programme will consider the vexed issues of donor procedures, eligibility to access assisted reproduction, and embryo research.
Papers are now being called for the afternoon session of the symposium, which will address the three areas above, in concurrent programme sessions. If you are interested in presenting a paper, please email hszoke@ita.org.au for an outline of the programme themes.

Registrations are also now being called for the symposium. Only one hundred places are available so early registration is advised. For a copy of the registration form please email: hszoke@ita.org.au or write to: The State of ART Symposium, c/- ITA, 30/570 Bourke Street, Melbourne, Victoria, Australia 3000. The registration fee will be $\$ 100.00$ and the venue will be University College, College Crescent, Parkville.

For further information please contact: Helen Szoke, ITA, 30/570 Bourke Street, Melbourne, Victoria, Australia 3000. Ph: 6138601 5250; fax: 613 8601 5277; email: hszoke@ita.org.au 